\title{
Romanelli, S. (2013). Gênese do processo tradutório. Editora Horizonte: Vinhedo. 181 p.
}

In a widely quoted definition, Clifford Geertz compares "doing ethnography" with "trying to read (in the sense of "constructing a reading of') a manuscript-foreign, faded, full of ellipses, incoherencies, suspicious emendations and tendentious commentaries, but written not in conventionalized graphs of sound but in transient examples of shaped behavior" (1973, p. 10). However, the new line of investigation in manuscript genetics opened by Romanelli, does the opposite. By constructing a reading of a translation manuscript in an attempt to uncover the intricacies of the underlying creative processes, the translation scholar behaves as an anthropologist who tries to understand the creative subject behind the cultural product.

Gênese do processo tradutório, the result of research carried out in a period of ten years by Sergio Romanelli at the Universities of Salvador de Bahia and Santa Catarina (Brazil), testifies to the excellent and burgeoning state of translation studies in Brazil. In his pioneering work, Romanelli explores new pathways situated at the crossroads of two disciplines, that is, manuscript genetics and translation studies. The novel interdisciplinary paradigm is introduced in a didactic way throughout the different chapters of the book.

In Chapter 1, following Philippe Willemart, Romanelli explains how chaos theory and the new insights into physics developed by Prigogine can be transferred to human sciences. Since the 1980s, the old assumptions of simplicity, stability and objectivity have been left behind and replaced with assumptions of complexity, instability and (inter)subjectivity. The new focus on the 'chaotic' nature of systems offers excellent tools for the study of creative processes, which are inherently complex, unstable and subjective. Based on an analysis of Velázquez's painting Las meninas, Romanelli guides the reader from Prigogine's chaos theory to genetic criticism, and he convincingly shows the many intersections between both seemingly dissociated fields of study.

Parallel to the above-mentioned paradigm shift in physics, translation studies evolved from a prescriptive to a descriptive discipline during the 1980s. In Chapter 2, Romanelli evokes how Gideon Toury's Descriptive Translation Studies and Evan Zohar's Polysystem Theory led to the concept of translation as a creative product embedded in a complex social field. It is both the descriptive and polysystem approaches to translation that allow Romanelli to build a disciplinary bridge between translation studies and manuscript genetics. Founded in France by Louis Hay in 1968, genetic criticism became institutionalized during the 1970s with the foundation of ITEM (Institut des Textes et Manuscrits 
Modernes), which is dedicated to the study of literary manuscripts. The aim of genetic criticism has been to unveil the process of artistic creation by observing and analysing the interventions of the text producer as part of a polysystem characterized by norms (aesthetic, social, linguistic, etc.). This is exactly what the descriptive translator scholar does. It has been Romanelli's merit to take the logical step of bringing together both disciplines interested in understanding the complexities of text creation.

After initiating the reader into the specific jargon and procedures of manuscript genetics, Chapters 3 and 4 deal with the preparatory phases of entering the field (if we may use the ethnographers' jargon). In this stage, the 'dossier' has to be prepared, including data on the author of the 'source' text as well as data on the translation manuscript and on the author/translator. Gênese do processo tradutório introduces the reader into the analysis of a double creative process: the translation of poetic work. As a case study, the author analyses the translation manuscripts of 114 poems (by Emily Dickinson) by the Italian translator and poet Rina Sara Virgillito. In a section called "Pre-genesis" (Chapter 3), Romanelli tries to reconstruct the 'polysystem' in which Dickinson's poems have been produced during the $19^{\text {th }}$ century. Chapter 4 introduces us to the context in which the poems were introduced in Italy and entered the life of Virgillito. Five notebooks discovered after Virgillito's death in 1996 constitute the corpus of Romanelli's analysis of the creative process of the poet/translator. This basic corpus containing the translation manuscript of the poems is investigated in the light of complementary information, such as the private library and other work (original or translation) of the poet/translator (Chapter 5).

Finally, the insights into Virigillito's creative translation process lead to some final thoughts in Chapter 6. According to Romanelli, it is important to restore the translator's dignity by fully recognizing him/her as a creator. This should be done not only by studying the product of the translators' creation (the translated text) but also by trying to understand the process constituted by successive creative acts. Such an enhanced understanding of manuscripts and of their "faded, full of ellipses, incoherencies, suspicious emendations, and tendentious commentaries", as Geertz would define them, probably will lead to a better understanding of the agency of the translator/creator. A next step (not contemplated, however, by Romanelli) would be to confront both the author's and the translator's creativity, based on a parallel scrutiny of the author's and translator's manuscripts.

It is striking that the Handbook of translation studies (Gambier \& Van Doorslaer, in its edition of 2012) still lacks an entry on 'Manuscript Genetics and Translation'. Although in today's translation studies, the agency of the translator as a creator has been fully acknowledged, the study of the material evidence of the creative process has so far been neglected. That is why in a scholarly field strongly dominated by English as a lingua franca, Romanelli's book deserves to be translated into 
English-but also into French and Spanish-to promote the further development of this fascinating interdisciplinary field of study.

\section{References}

Gambier, Y., \& Van Doorslaer, L. (Eds.) (2012). Handbook of translation studies. Amsterdam: John Benjamins.

Geertz, C. (1973). The interpretation of cultures. New York: Basic Books.

\section{Christiane Stallaert}

Universiteit Antwerpen, Belgium

christiane.stallaert@uantwerpen.be 